\title{
Comparative morphology of the spermatheca within the family Dinidoridae (Hemiptera: Heteroptera)
}

\author{
ANNA KOCOREK ${ }^{1}$ and TERESA DANIELCZOK-DEMSKA ${ }^{2}$ \\ Department of Biosystematics, University of Opole, Oleska 22, 45-052 Opole, Poland; e-mail: 'kocanka@uni.opole.pl., \\ 2danielcz@uni.opole.pl
}

Key words. Morphology, female, spermatheca, Hemiptera, Heteroptera, Dinidoridae

\begin{abstract}
The spermathecae of eleven genera of the family Dinidoridae (Dinidorinae and Megymeninae) were studied. Four types of spermatheca morphology were observed. Possible use of the morphology of spermathecae in the taxonomy of Dinidoridae is discussed.
\end{abstract}

\section{INTRODUCTION}

The spermatheca is an accessory female reproductive organ which, occurs in all orders of insects except for Protura and Collembola (Matsuda, 1976). It is a complex organ and varies greatly in shape and histology between groups (Pendergrast, 1957). In some Heteroptera the spermatheca has been completely lost, in others it has lost its primary function of storing sperm (Dupuis \& Carvalho, 1956; Dupuis, 1970; Schuh \& Slater, 1995). The spermatheca is present in all Pentatomoidea and usually consists of a spermathecal duct, leading from the vagina to a dilated spermathecal bulb, and is characterised by a well marked pumping region with proximal and distal flanges (McDonald, 1966). The spermathecal bulb is covered by secretory cells located outside the epithelium of the spermatheca. The spermatheca plays a significant role in many functions e.g.: sperm storage, copulation, fertilization, oviposition (Gaffour-Bensebban, 1991, 1994).

The first study on spermathecae was carried out by Dufour (1833), who erroneously regarded this organ as a sebaceous gland in which oil may have been produced. Von Siebold (1837) published the earliest correct description of a spermatheca (as receptaculum seminis) in Pentatomomorpha. For Dinidoridae, the first study of the morphology of spermatheca was published by Yang (1940) for some species of Chinese Dinidoridae. In the fifties, three fundamental works on the structure of the female genitalia in Heteroptera were published by Dupuis (1955), Pendergrast (1957) and Scudder (1959). A very important work on the male and female genitalia of Pentatomoidea was published by Kumar (1962) and McDonald (1966). All the above works demonstrated that the structure of the genitals of insects might be used in taxonomic studies. Servadei (1964) gave a detailed description of spermathecae of Acanthosomatidae, Pentatomidae and Scutelleridae (as Scutellerinae), with an original key to subfamilies and genera. Some additional, although incidental, information on the pentatomoid spermatheca in single species can be found in the many taxonomic studies. For Dinidoridae the most valuable is the revision made by Durai (1987), however, even here spermatheca was not treated in great detail.

This study examines the morphology of the spermatheca in Dinidoridae and also establishes their taxonomic importance.

\section{MATERIALS AND METHODS}

The specimens used in this study were selected from dried museum material obtained from the following institutions: Bernice P. Bishop Museum, Honolulu, Hawaii, USA (BPBM); Hungarian Natural History Museum, Budapest, Hungary (HNHM); Ernst Heiss Collection, Innsbruck, Austria (EHIA); Muséum National d'Histoire Naturelle, Paris, France (MNHN); South Australian Museum, Adelaide, Australia (SAMA); Zoologisches Institut und Museum, Hamburg Universität, Hamburg, Germany (ZMUH); Museum and Institute of Zoology, Polish Academy of Sciences, Warsaw, Poland (ZMPA); Department of Biosystematics, Section of Zoology, University of Opole, Poland (DBUO).

Representatives of eleven (out of 16) genera of Dinidoridae were studied which includes all the types of spermatheca. Altogether, 85 females from the following 34 species were studied (the classification follows that of Kocorek \& J. A. Lis, 2000).

To prepare the spermatheca we first soaked the abdomen in $10 \% \mathrm{KOH}$ for 1 to 5 minutes to soften it. Then tissues were removed and the spermatheca was exposed by fine dissection. Cleared spermatheca was placed in glycerine. Observations were made using standard optical equipment (stereoscopic microscope with a magnification of 32x). The terminology used follows that of Pendergrast (1957), Scudder (1959), and McDonald (1966).

The following morphological characters of the spermatheca were used to characterize the types;

1. the shape of the spermathecal bulb

2. the size of the proximal and distal flange

3. the shape and size of the spermathecal duct

4. the presence of additional outgrowths

5. the presence of sclerites

\section{RESULTS}

\section{Dinidorinae: Dinidorini}

Cyclopelta Amyot \& Serville, 1843 (Figs 1-4) - spermathecal bulb large, spherical; pump flanges in: $C$. 

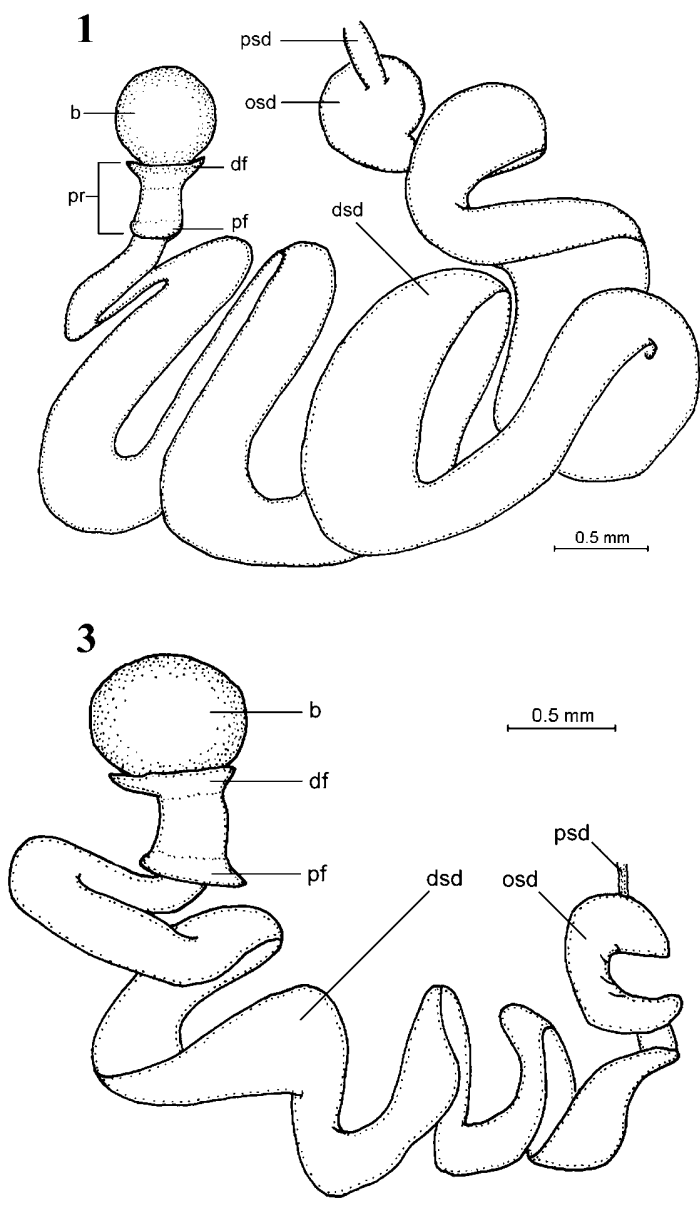

2
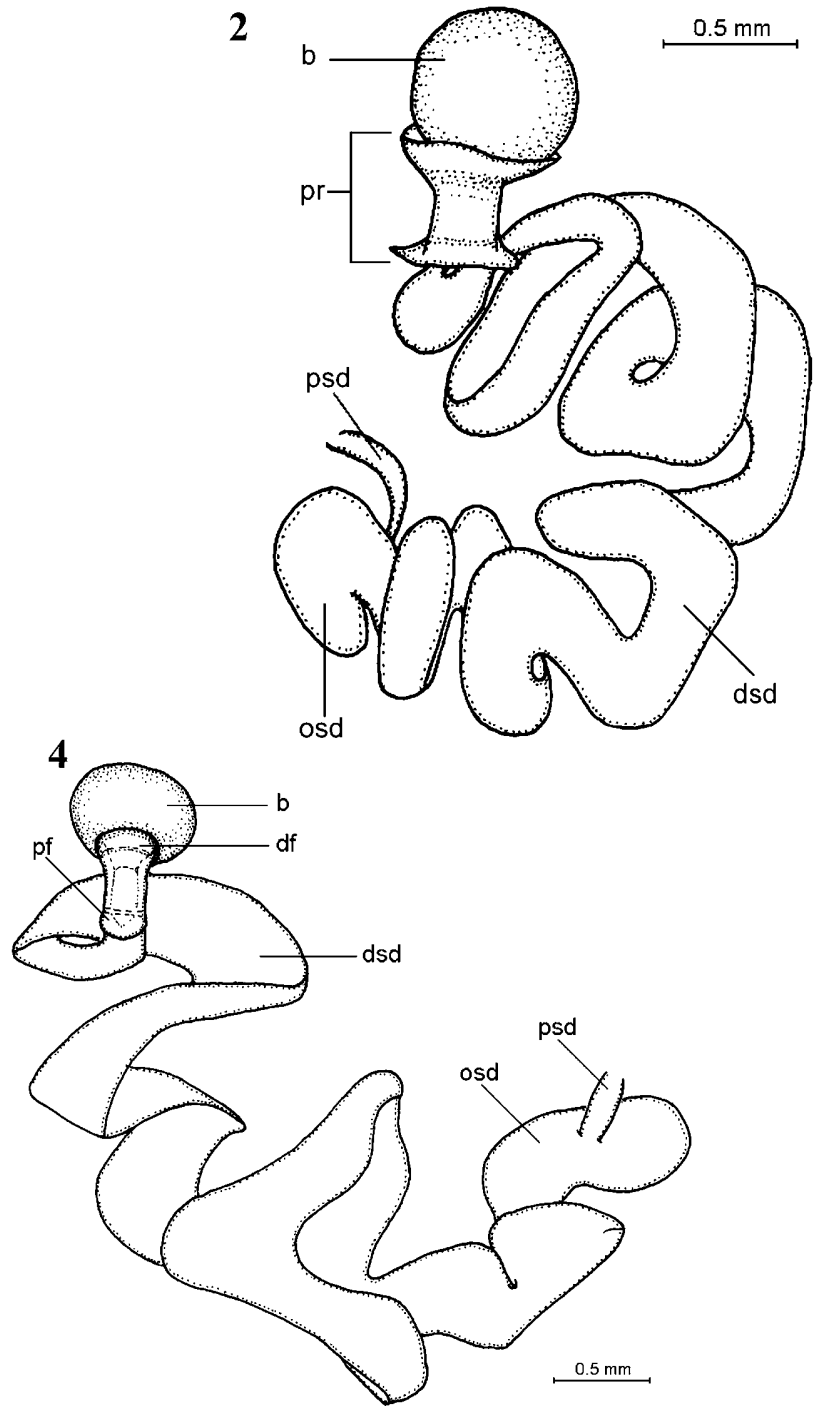

Figs 1-4. Spermatheca. 1-Cyclopelta tristis; 2 - C. obscura; 3 - C. funebris; 4 - C. bechynei. Abbreviations: $\mathrm{b}-\mathrm{bulb}, \mathrm{df}-\mathrm{distal}$ flange, dsd - distal part of the spermathecal duct, osd - outgrowth of the spermathecal duct, pf - proximal flange, pr - pumping region, psd - proximal part of the spermathecal duct.

obscura - very well developed and almost equal in size, C. funebris - flanges developed, the distal one larger than the proximal one, sometimes the proximal flange reduced, C. bechynei - flanges very small; in all these cases the distal flange adheres closely to the bulb; the spermathecal duct diverse, divided into two parts: a very short, proximal (psd) and a long, flattened distal part (dsd), which is relatively wide, helically curved with a small outgrowth (osd); sclerites absent.

Material examined. Cyclopelta obscura (Lepeletier \& Serville., 1828), 4 ex., Soekaranda, Java (ZMPA), 1ex., Batu (DBUO); C. tristis (Stål, 1864), 5 ex., Africa (ZMPA, DBUO); C. funebris (Fabricius, 1775), 3 ex., Africa (DBUO); $C$. bechynei Durai, 1987, 1 ex., Togo (DBUO).

Note. Spermatheca of $C$. obscura is similar to that of $C$. ornata Stål, 1870 (of Durai, 1987), flanges of C. bechynei Durai, 1987, are similar to those of C. solmani J.A. Lis, 1990 (of J.A. Lis, 1990)

Coridius Illiger, 1807 (Figs 5-19) - spermathecal bulb large, spherical; pump region well defined, flanges medium-sized and adhere to the bulb; the spermathecal duct dilated (dpsd) along its whole length with one (A) or two (B) outgrowths:

A - one outgrowth (varying in size and shape): $C$. ianus, C. viduatus, C. putoni - a very long ribbon-like additional outgrowth (osd); C. prolixus, $C$. duraiae, - a medium-sized outgrowth like a sack (osd); C. nubilus small outgrowth (osd).

B - two outgrowths: C. xanthopterus, $C$. nepalensis, $C$. chinensis, C. brunneus - a large and elongated one (osd1), and a small one (osd2); C. fuscus, C. affinis, C. remipes, C. cuprifer, C. castaneus - similar to the one described above (osd2), but the outgrowth (osd1) smaller and not so elongated.

Material examined. Coridius ianus (Fabricius, 1775), 2 ex. India (ZMPA); C. viduatus (Fabricius, 1794), 3 ex. Tanzania (DBUO), 1ex. Cameroon (ZMPA); C. putoni (Bolivar, 1879), 3 ex. Zimbabwe (ZMPA) 1 ex. Tanzania (Singida) (DBUO); $C$. prolixus (Lethierry, 1881) 2 ex. Cameroon (DBUO); C. duraiae J. A. Lis, 1990, 2 ex. Cameroon (DBUO); C. nubilus (West- 

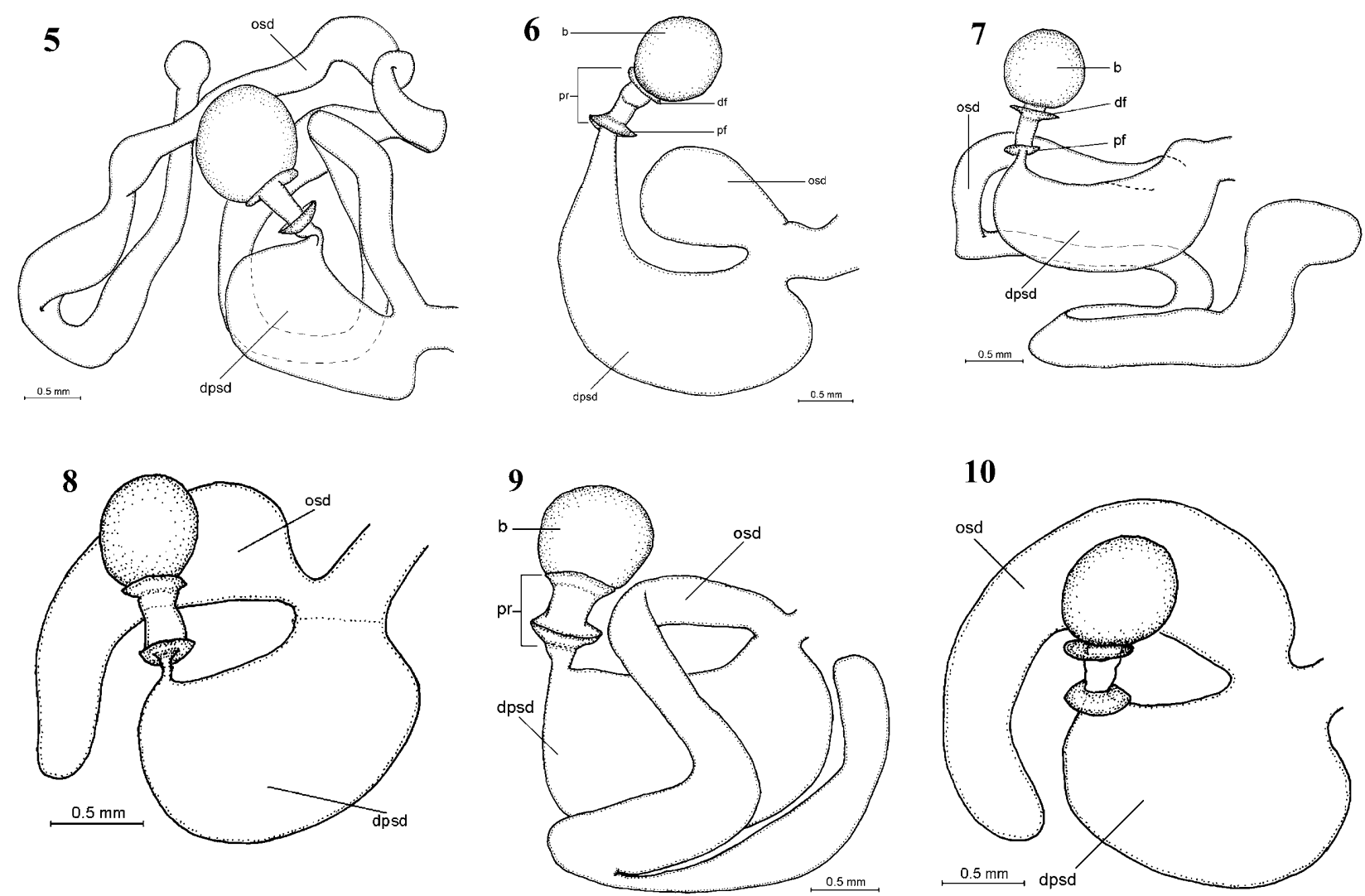

Figs 5-10. Spermatheca. 5 - Coridius ianus; 6 - C. nubilus; 7 - C. putoni; 8 - C. prolixus; 9 - C. viduatus; $10-$ C. duraie. Abbreviations: $b$ - bulb, df - distal flange, dpsd - dilated portion of the spermathecal duct, osd - outgrowth of the spermathecal duct, $\mathrm{pf}$ - proximal flange, $\mathrm{pr}$ - pumping region.

wood, 1837), 2 ex. Zimbabwe (ZMPA); C. xanthopterus (Fairmaire, 1858), 7 ex. Cameroon, Guinea (DBUO) C. nepalensis (Westwood, 1837), 1 ex. Sumatra (ZMPA); C. chinensis (Dallas, 1851), 2 ex. Laos (DBUO); C. brunneus (Thunberg, 1783), 2 ex. India (Calcutta), 1 ex. Java (ZMPA); C. fuscus (Westwood, 1837), 2 ex. Java (ZMPA, DBUO); C. affinis (Costa, 1847), 1ex. Java (ZMPA); C. remipes (Stål, 1853), 4 ex. Cameroon (Old Calabar) (ZMPA), Cameroon, Togo (DBUO); C. cuprifer (Westwood, 1837), 2 ex. Cameroon (DBUO); C. castaneus (Signoret, 1861), 2 ex. Madagascar (ZMPA).

Note. Spermatheca of C. flavomarginatus (Signoret, 1861), is similar to that of C. brunneus in that it has two outgrowths (Durai, 1987).

Dinidor Latreille, 1829 (Fig. 29) - spermathecal bulb small, spherical; pump flanges well developed, medium sized, the proximal one larger than the distal one, the distal flange does not adhere to the bulb; the spermathecal duct very light and membranous, dilated along its whole length (balloon-like dilation); outgrowths and sclerites absent.

Material examined. Dinidor rufocinctus (Stål, 1870), 1 ex., Chiriqui (ZMPA).

Note. Spermatheca of Dinidor impicticollis (Stål, 1870), D. pulsator Schouteden, 1913, D. mactans (Fabricius, 1798), is very similar to that of D. rufocinctus (Stål, 1870), in having a very light and membranous duct, (Durai, 1987).

Sagriva Spinola, 1850 (Fig. 35) - spermathecal bulb spherical, medium-sized, well developed but with small flanges, the proximal one larger than the distal one, the distal flange does not closely adhere to the spermathecal bulb; spermathecal duct long and thin, dilated and sclerotized proximally (sack-like dilation); outgrowths absent.

Note. A monotypic genus (Sagriva vittata Spinola, 1850), material for this genus was not available; data presented by Durai (1987) were used.

Colpoproctus Stål, 1870 (Fig. 33) - spermathecal bulb differed from the others examined: large and has an elongated balloon-like shape; flanges distant from the bulb; spermathecal duct long and thin, dilated proximally (sacklike dilation) with one curved tubular outgrowth (cosd); sclerites absent.

Material examined. Colpoproctus pullus (Stål, 1853), 1 ex. East Africa (DBUO);

Note. Spermatheca of C. pullus similar to that of C. vilis (Walker, 1868), (of Durai, 1987)

\section{Dinidorinae: Thalmini}

Thalma Walker, 1868 (Fig. 31) - spermathecal bulb of medium size, spherical; pumping region well defined with proximal and distal flanges; the proximal flange larger than the distal one, which does not adhere to the bulb; spermathecal duct narrow, short and light, distincty dilated and sclerotized proximally; outgrowths and sclerites absent. 

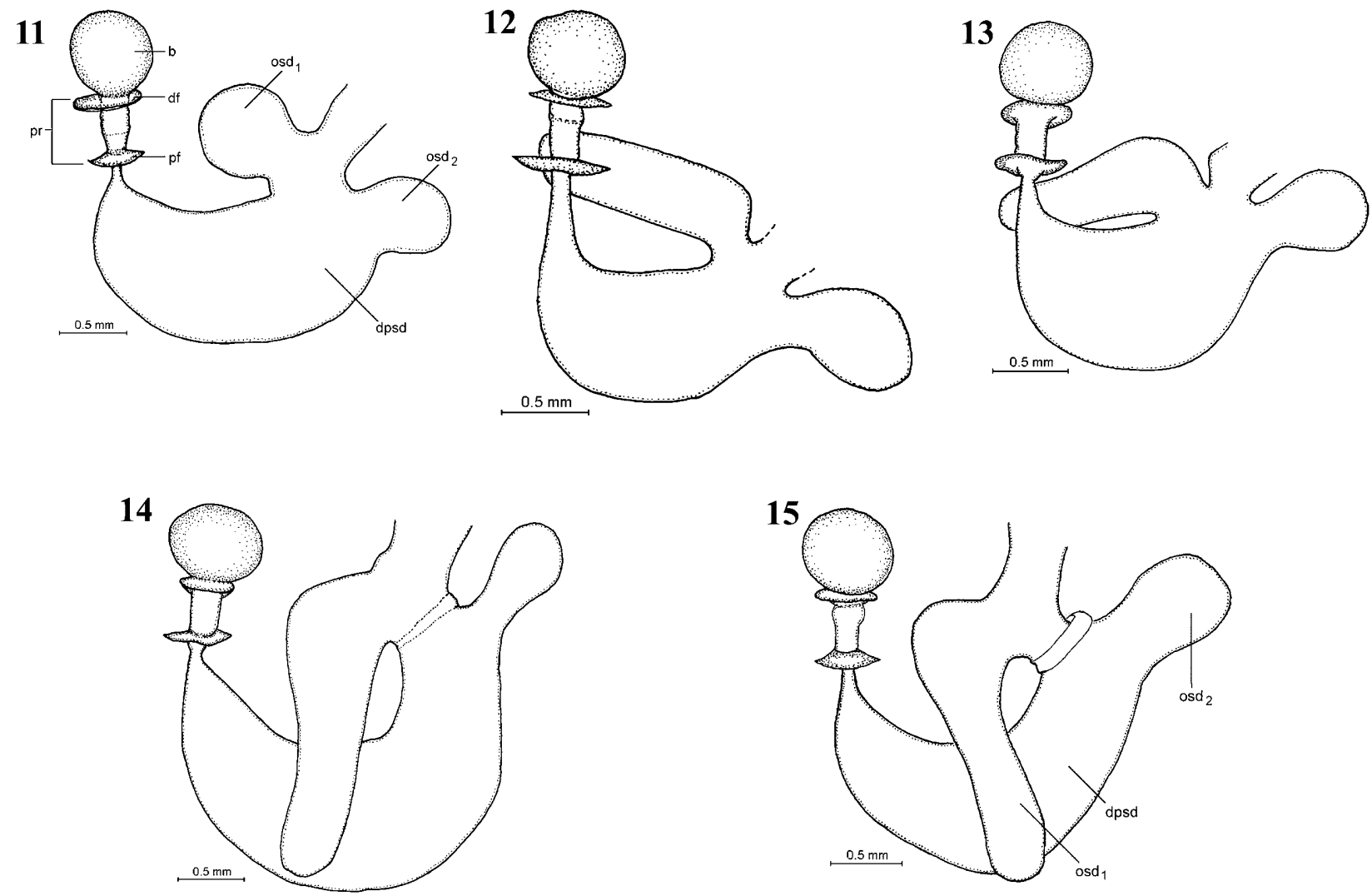

Figs 11-15. Spermatheca. 11 - Coridius castaneus; 12 - C. affinis; $13-$ C. fuscus; $14-$ C. remipes; 15 - C. xanthopterus. Abreviations: $\mathrm{b}$ - bulb, $\mathrm{df}$ - distal flange, dsd - distal part of the spermathecal duct, osd - outgrowth of the spermathecal duct, $\mathrm{pf}-$ proximal flange, $\mathrm{pr}-$ pumping region.

Material examined. Thalma secunda J.A. Lis \& Kocorek, 1996, holotype, New Guinea (MNHN).

Note. Spermatheca of Thalma biguttata Walker, 1868, is very similar to that of T. secunda J.A. Lis \& Kocorek, 1996, in the shape of spermathecal duct, which is divided into two parts: short and narrow distal part and large dilated proximal part (Durai, 1987).

Folengus Distant, 1914 (Fig. 36) - spermathecal bulb, spherical, medium sized; flanges well developed, both similar in size; spermathecal duct long and tubular, distinctly enlarged proximally; additional outgrowth present as a tubular branch of the spermathecal duct.

Note. Material of this genus was not available; it is a monotypic genus (Folengus papuensis Distant, 1914); data presented is that of Durai (1987).

\section{Megymeninae: Megymenini}

Megymenum Guérin-Méneville, 1831 (Figs 20-28) spermathecal bulb spherical, small or of medium size; pumping region well defined, distal and proximal flanges distinct and large (in $M$. spinosum the distal one smaller than the proximal one, in $M$. brevicorne the proximal one smaller than the distal one, in other species equal in size); distal flange clearly separated from the spermathecal bulb; spermathecal duct dilated along its whole length (sack-like), sometimes light, membraneous, sometimes sclerotized with numerous folds containing minute spines (thorny or point-like) specific for each species; ring sclerite present; outgrowths absent.
Material examined. Megymenum dentatum Guérin, 1831, 5 ex., New Guinea (BPBM, SAMA, ZMPA); M. spinosum (Burmeister, 1834), 3 ex., Java, Borneo (ZMPA, DBUO); $M$. brevicorne (Fabricius, 1787), 2 ex., India (MNHN), 2ex., China, Canton (ZMUH, DBUO); $M$. semivestitum Vollenhoven, 1868, 1ex., Indonesia, Amboina (ZMPA); M. megaspinosum Kocorek, 2000, holotype, Sumatra (ZMUH); M. gracilicorne Dallas, 1851, 3ex., Japan (MNHN, DBUO); M. pratti Distant, 1911, 3ex., China, Yunnan (MNHN, ZMPA); M. parallelum Vollenhoven, 1868, 3ex., Java (ZMPA, DBUO).

Doesbergiana Durai, 1987 (Fig. 30) - spermathecal bulb large and spherical; distal and proximal flanges distinct and large, equal in size; distal flange separated from spermathecal bulb; the spermathecal duct dilated along its whole length, sac-like, membranous; without outgrowths; ring sclerites present.

Note. A monotypic genus (Doesbergiana borneoensis Durai, 1987) not available for study; data presented is that of Durai (1987)

Eumenotes Westwood, 1844 (Fig. 34) - spermathecal bulb spherical; distal and proximal flanges distinct and equal in size; spermathecal duct thin and light, widened proximally into a slight enlargement; outgrowth and sclerites absent.

Materiał examined. Eumenotes obscura Westwood, 1844, 3 ex., Indonesia, Sumatra (HNHM, EHIA). 

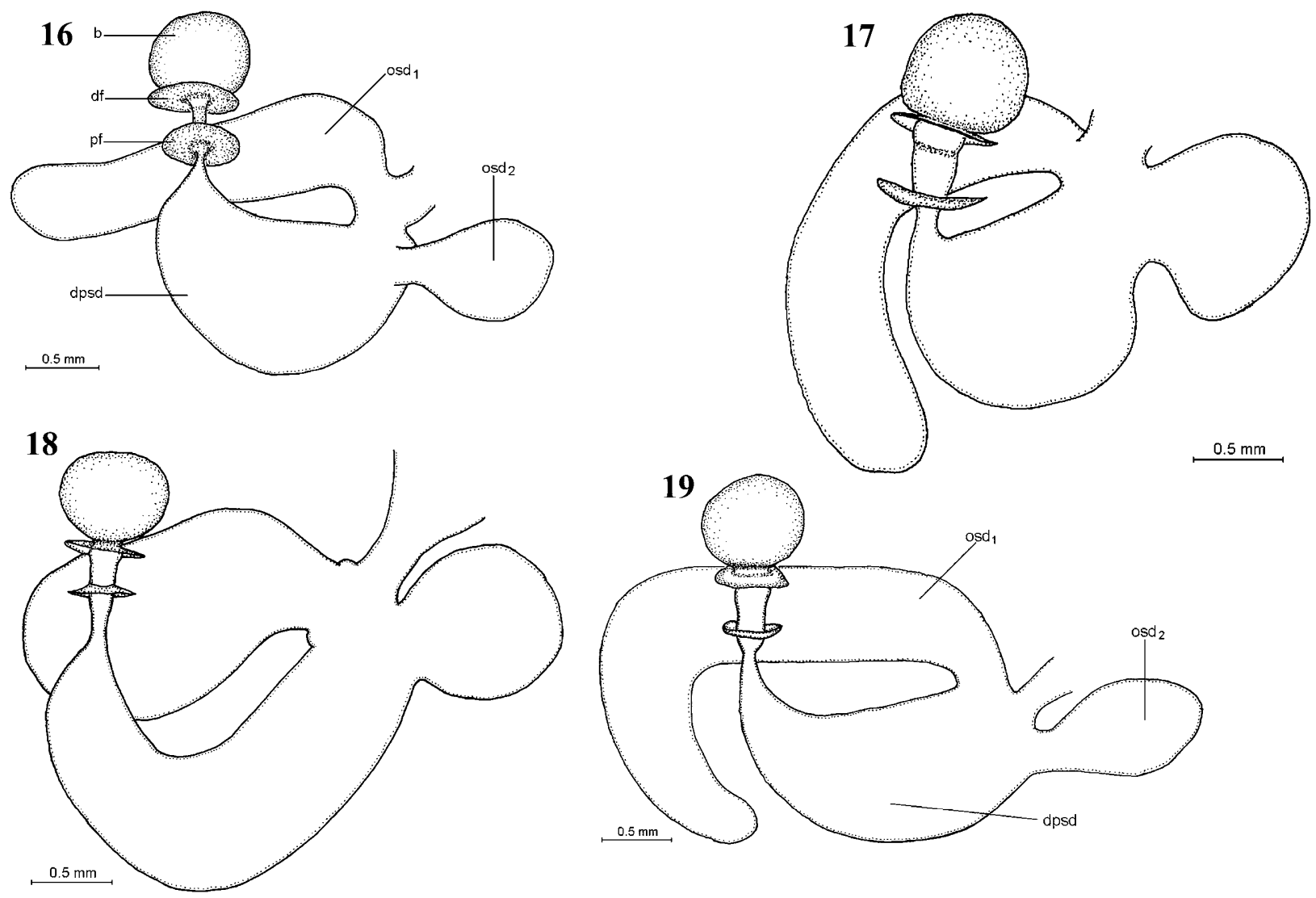

Figs 16-19. Spermatheca. 16 - Coridius brunneus; $17-$ C. chinensis; $18-$ C. cuprifer; $19-$ C. nepalensis. Abbreviations: b bulb, df - distal flange, dpsd - dilated portion of the spermathecal duct, osd - outgrowth of the spermathecal duct, pf - proximal flange.

\section{Megymeninae: Byrsodepsini}

Byrsodepsus Stål, 1872 (Fig. 32) - spermathecal bulb large and spherical; distal and proximal flanges distinct and large, distal one much bigger, does not adhere to the bulb; the spermathecal duct very long and thin, dilated proximally (forming a large spherical sac); outgrowths and sclerites absent.

Material examined. Byrsodepsus sundanus Breddin, 1900, holotype, Soekaranda (Indonesia, Sumatra) (ZMPA).

\section{DISCUSSION}

The results of our study show that there is no uniform type of spermatheca in the Dinidoridae. Analysis of its structural characters has demonstrated that four main types of spermatheca can be distinguished in this family: type I "cyclopeltic", type II "coridious", type III "megymenic" and type IV "mixed". In some cases it is difficult to specify unambiguously the type (e.g. in the genus Folengus).

Type I "cyclopeltic" (Figs 1-4) - occurs in the genus Cyclopelta - the main features distinguishing it from other types are: the bulb is large and spherical, flanges not clearly marked, distal one closely embracing the bulb, the spermathecal duct divided into two parts: proximal part short, in the form of a narrow duct, and the distal part long and flattened, relatively wide, helically curved, the border between the proximal and the distal parts marked by a small outgrowth; sclerites absent.

Type II "coridious" (Figs 5-19) - is characteristic of the genus Coridius; this type was divided into two subtypes according to the presence of one (subtype A) or two (subtype B) outgrowths. The spermathecal bulb is spherical and large, the flanges are of medium size or sometimes small, the distal one protrudes, in some cases it adheres slightly to the bulb (C. viduatus, C. nubilus, C. ianus); spermathecal duct dilated, with one or two outgrowths:

IIA (Figs 5-10) - with one outgrowth: long or very long, ribbon-like outgrowth (osd) or of medium length, sometimes short, sack-shaped;

IIB (Figs 11-19) - with two outgrowths: outgrowth 1 (osd1) - of medium size, varies in individual species $(C$. castaneus - very short), and outgrowth 2 (osd2) - not large, bulge-like.

In all the cases there are no sclerites.

Type III "megymenic" (Figs 20-30) - occurs in: Megymenum, Doesbergiana and Dinidor and is characterized by: spherical bulb of a medium size, large flanges, protruding from the bulb (exception Dinidor - small flanges); spermathecal duct strongly enlarged and widened, sack-like; outgrowths absent; ring sclerite present, in the genus Megymenum small, numerous spines present. 

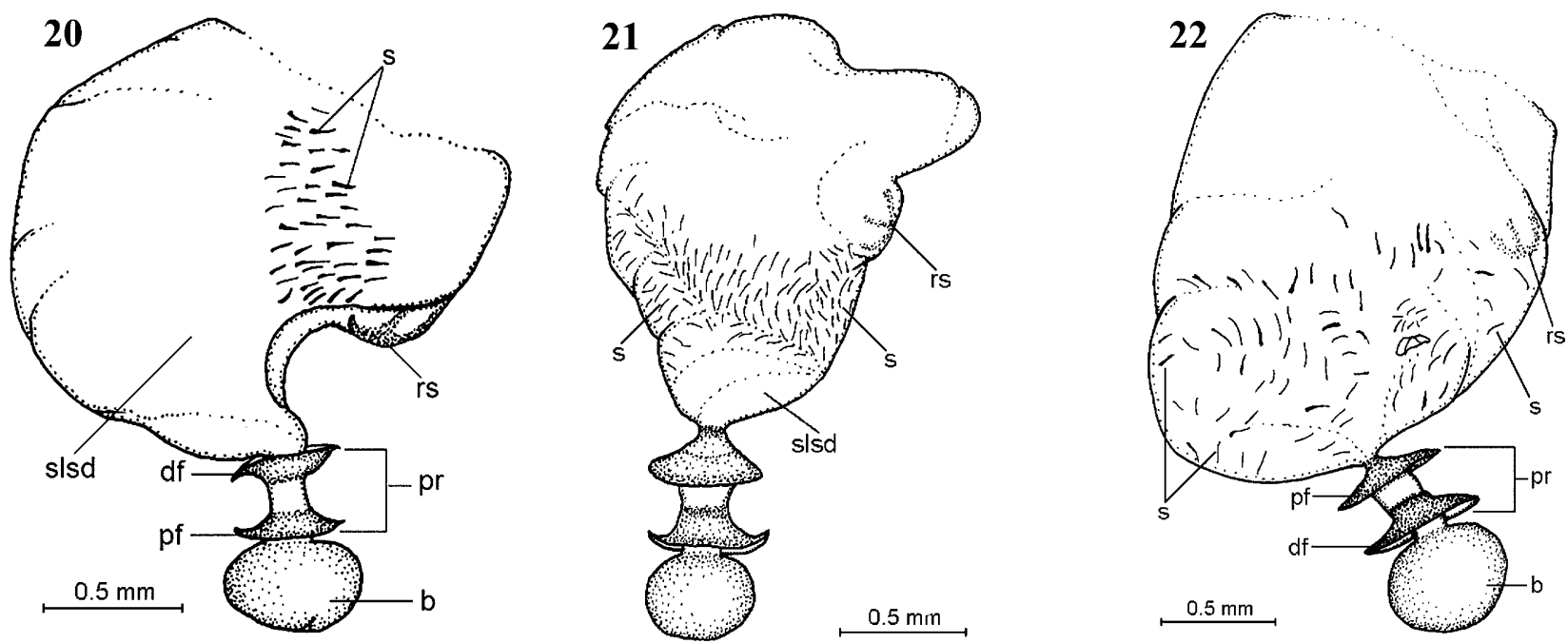

23

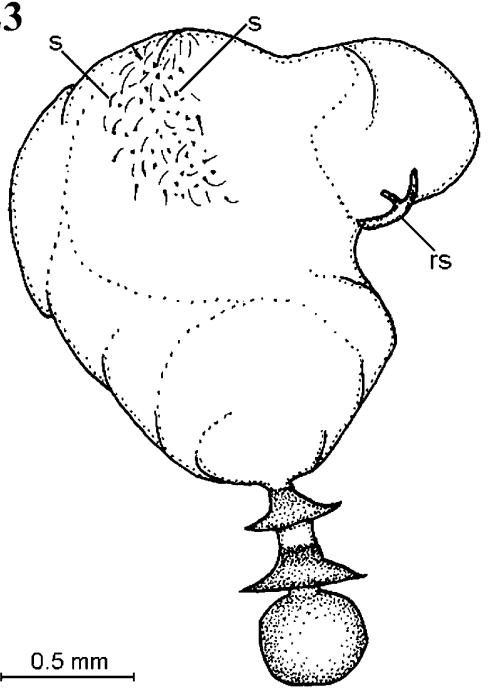

24

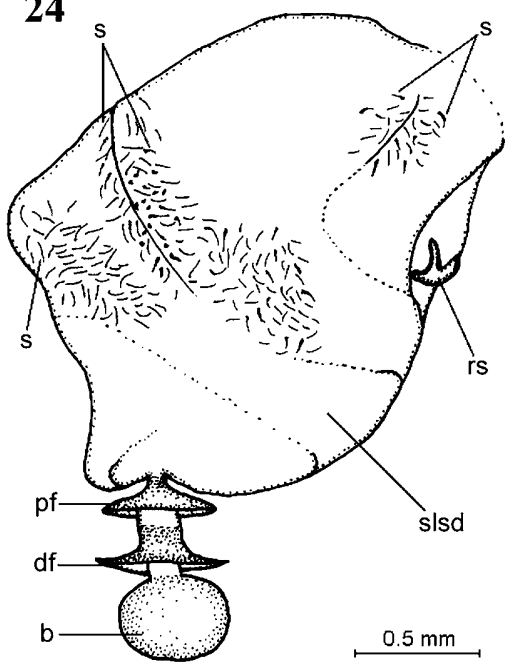

25

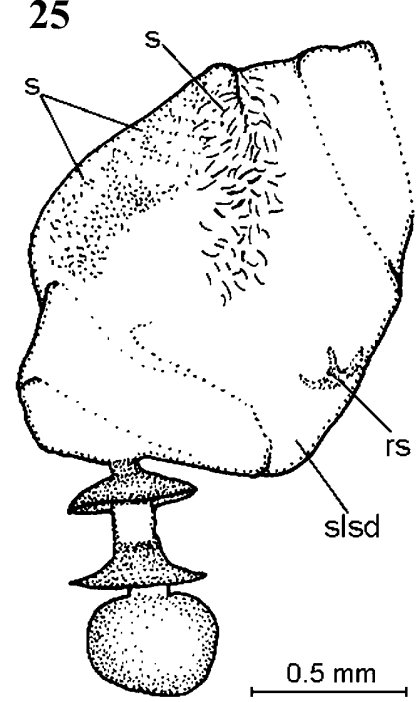

Figs 20-25. Spermatheca. 20 - Megymenum brevicorne; 21 - M. megaspinosum; 22 - M. semivestitum 23 - M. gracilicorne; 24 M. parallelum; 25 - M. pratti. Abbreviations: $\mathrm{b}$ - bulb, $\mathrm{df}$ - distal flange, $\mathrm{pf}$ - proximal flange, $\mathrm{pr}$ - pumping region, $\mathrm{rs}-\mathrm{ring}$ sclerite, $\mathrm{s}-$ spines, slsd - sac-like spermathecal duct.

Type IV "mixed" (Figs 31-36) - occurs in the genera: Byrsodepsus, Thalma, Eumenotes, Colpoproctus, Sagriva, Folengus - it is characterized by: spherical bulb, of medium size (except in Colpoproctus - balloon-like, elongated), the flanges of the pump are distinct, the spermathecal duct strongly widened in its proximal part, its distal part tube-like, varying in length; outgrowths absent, except in Folengus and Colpoproctus, where additional cylindrical outgrowth is present.

To summarise, the spermatheca is characterized by:

- spermathecal bulb is spherical and very close to the pumping region in all cases, either directly attached to the pump, or connected to it by a short duct (except in Colpoproctus pullus - Fig. 33),

- proximal and distal flanges well developed except in Cyclopelta bechynei (Fig. 4),

- the whole spermathecal duct either widened or expanded in the proximal part only,
- in some cases outgrowths present, a very characteristic feature in type II - "coridious"

- two types of sclerites present (ring sclerite and spines) in type III - "megymenic".

In all the cases it is possible to identify the genus, and in some cases even the species, that a given specimen belongs to from the structure of its spermatheca. Thus the shape of the spermatheca is genus-specific.

No tribe-specific type of spermatheca was observed in Dinidoridae. In the Dinidorini we have traced four types: Cyclopelta - type I "cyclopeltic," Coridius - type II "coridious," Dinidor - type III "megymenic," Colpoproctus and Sagriva - type IV "mixed." In Megymenini two types were described: Megymenum and Doesbergiana - type III "megymenic," and Eumenotes - type IV "mixed." A single type ("mixed") occurs only in Thalmini (Thalma and Folengus) and Byrsodepsini (Byrsodepsus). Probably there is a lot of homoplasy in the shape of sper- 
26

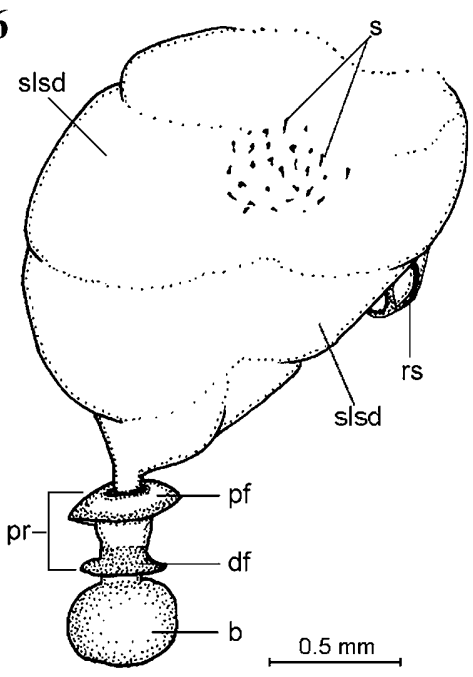

29

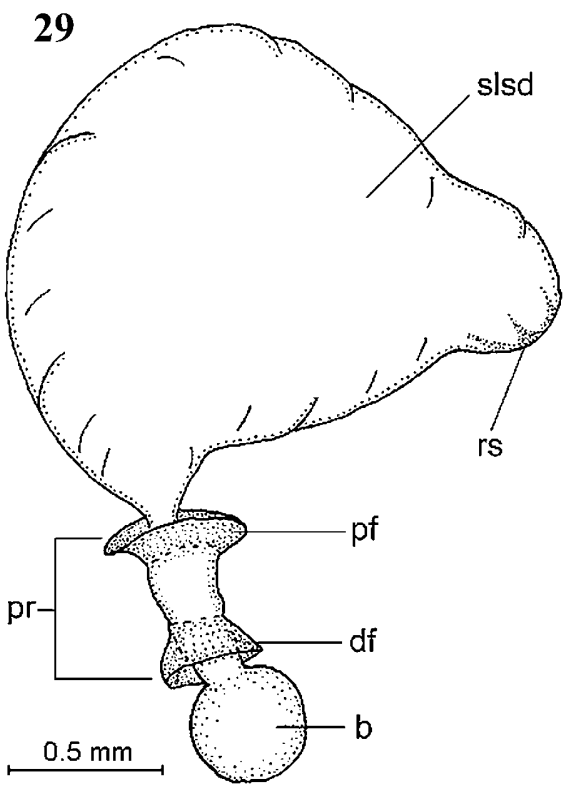

27

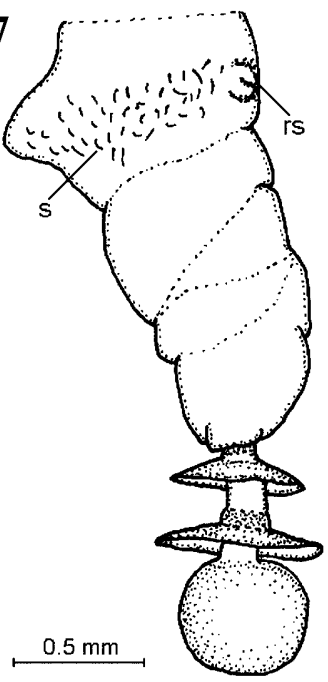

28

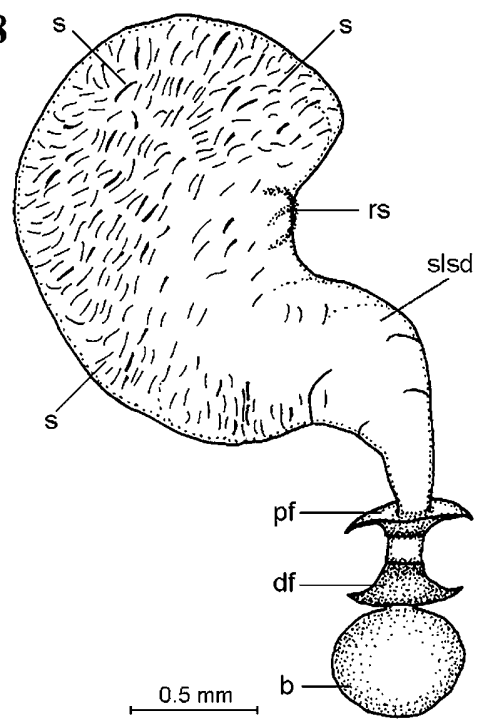

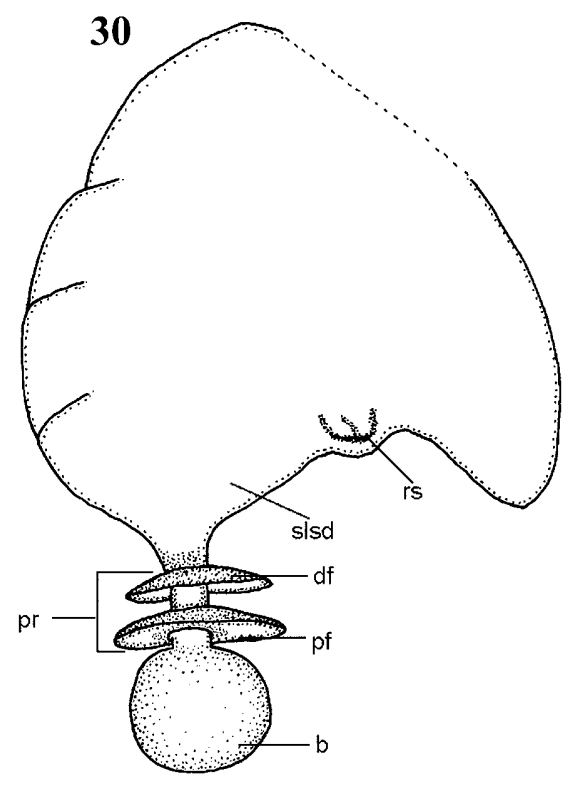

Figs 26-30. Spermatheca. 26 - Megymenum spinosum; 27 - M. mekongum; 28 - M. dentatum; 29 - Dinidor rufocinctus; 30 Doesbergiana borneoensis (Fig. 30 from Durai, 1987). Abbreviations: b - bulb, df - distal flange, pf - proximal flange, pr pumping region, $\mathrm{rs}$ - ring sclerite, $\mathrm{s}$ - spines, slsd - sac-like spermathecal duct.

mathecae or the tribes may not be monophyletic. In addition, a number of genera within the Dinidorini might have been wrongly deliminated and their systematic position needs reconsideration. The structure of spermatheca cannot be the sole basis for such radical changes; it does, however, indicate that the above mentioned taxons should be revised.

ACKNOWLEDGEMENTS. We would like to thank Professor Jerzy A. Lis for access to his material of Dinidoridae and for critical review of the manuscript. We would also like to express our gratitude to the following for the loan of material: K. Kami (BPBM), T. Vásárhelyi (HNHM), E. Heiss (EHIA), D. PluotSigwalt (MNHN), J. Forrest (SAMA), H. Strümpel (ZIZM), E. Hałka-Wojciechowicz (ZMPA). Thanks are also extended to Dr. Hubert Wojtasek for reading the manuscript.

\section{REFERENCES}

Dufour L. 1833: Recherches anatomiques et Physiologiques sur les Hémiptères. Mém. Pres. Acad. Sci., Paris 4: 133-461. [in French]

Dupuis C. 1955: Les génitalia des Hémiptères Hétéroptères (Génitalia externes des deux sexes; Voies ectodermiques femelles). Revue de la morphologie. Lexique de la nomenclature. Index bibliographique analytique. Mém. Mus. Hist. Nat. Paris 6: 183-278. [in French]

Dupuis C. 1970: Heteroptera. In Tuxen S.L., (ed.): Taxonomist's Glossary of Genitalia in Insects. Munksgaard International Booksellers and Publishers, Copenhagen, pp. 190-209.

Dupuis C. \& Carvalho J.C.M. 1956: Heteroptera. In Tuxen S. L., (ed.): Taxonomist' Glossary of Genitalia in Insects. EJNAR Munksgaard, Copenhagen, pp. 158-169.

DURAI P.S.S. 1987: A revision of the Dinidoridae of the World (Heteroptera: Pentatomoidea). Orient. Ins. 21: 163-360. 
31

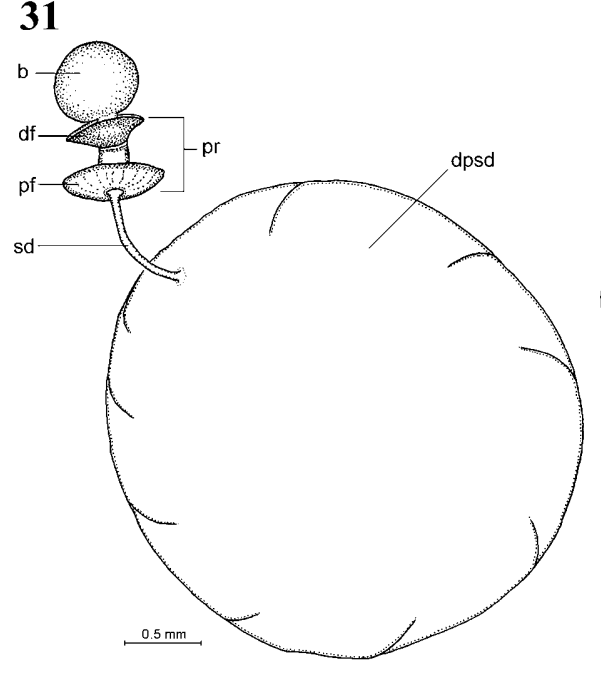

32

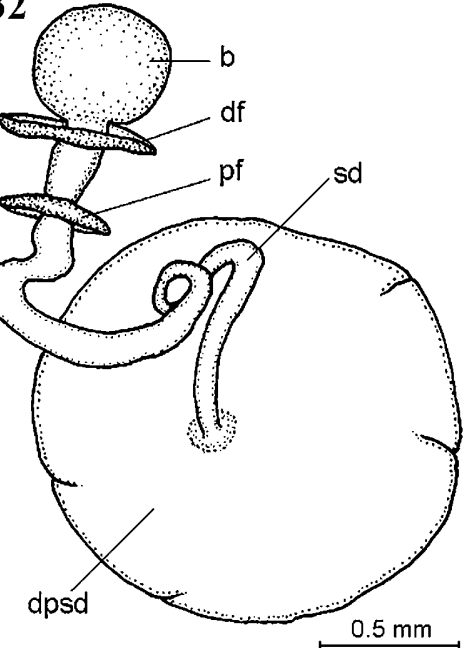

33
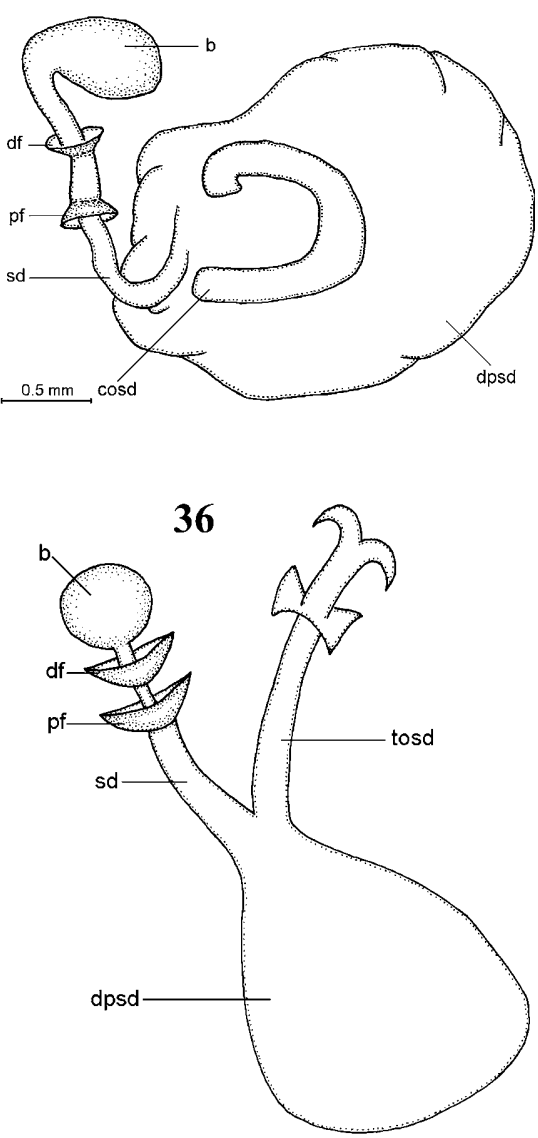

Figs 31-36. Spermatheca. 31 - Thalma secunda; 32 - Byrsodepsus sundanus; 33 - Colpoproctus pullus; 34 - Eumenotes obscura; 35 - Sagriva vittata; 36 - Folengus papuensis (Figs 35 \& 36 from Durai, 1987). Abbreviations: b - bulb, cosd - curved outgrowth of the spermathecal duct, df - distal flange, dpsd - dilated portion of the spermathecal duct, pf - proximal flange, pr - pumping region, sd - spermathecal duct, tosd - tubular outgrowth of the spermathecal duct.

GafFour-Bensebbane C. 1991: Morphologie des voies genitales ectodermiques des femelles d'Eurygaster austriaca (Schrank, 1776) [Het.: Scutulleridae]. Bull. Soc. Entomol. Fr. 95(7-8): 209-227. [in French, English abstr.]

GafFour-Bensebbane C. 1994: Les variations morphologiques de l'appareil genital ectodermique des femelles de Scutelleridae (Heteroptera, Pentatomoidea). Nouv. Revue Entomol. 11: 267-281. [in French, English abstr.]

Kocorek A. \& Lis J.A. 2000: A cladistic revision of the Megymeninae of the World (Hemiptera: Heteroptera: Dinidoridae. Pol. J. Entomol. 69: 7-30.

Kumar R. 1962: Morpho-Taxonomical Studies on the Genitalia and Salivary Glands of some Pentatomoidea. Entomol. Tidskrift 83: 44-84.

Lis J.A. 1990: New Genera, New species, new records and checklist of the old world Dinidoridae (Heteroptera: Pentatomoidea). Ann. Upp. Siles. Mus., Entomol. 1: 103-147.

Matsuda R. 1976: Morphology and Evolution of the Insect Abdomen. Oxford: Pergamon Press, Oxford, $534 \mathrm{pp}$.

McDonald F.J.D. 1966: The genitalia of North American Pentatomoidea (Hemiptera: Heteroptera). Quaest. Entomol. 2: $7-150$.
Pendergrast J.G. 1957: Studies on the reproductive organs of the Heteroptera with a consideration of their bearing on classification. Trans. R. Entomol. Soc. Lond. 109: 1-63.

Schun R.T. \& Slater J.A. 1995: True Bugs of the World (Hemiptera: Heteroptera), Classification and Natural History. Cornell University Press, Ithaca and London, $337 \mathrm{pp}$.

ScUdDER G.G.E. 1959: The Female Genitalia of the Heteroptera: Morphology and Bearing on Classification. Trans. $R$. Entomol. Soc. Lond. 111: 405-467.

Servadei A. 1964: Il valore tassonomico delle spermateche degli emitteri eterotteri (Fam. Pentatomidae e Acanthosomatidae). Atti Accad Naz. Ital. Entomol. Rc. 11: 58-86. [in Italian].

Siebold von C.Tн. 1837: Fernere Beobachtungen über die Spermatozoen der wirbellosen Tiere. Arch. Anat. Physiol. Wiss. Medic. 1837: 381-439. [in German]

YANG WE-I. 1940: Systematical studies of Chinese Coridiinae with particular reference to the genitalia of both sexes. Bull. Fan. Mem. Inst. Biol. Zool. Serv. 1940: 1-40.

Received December 21, 2000; revised September 20, 2001; accepted November 21, 2001 